\title{
Consciência ambiental e proteção da água
}

\author{
Environmental awareness and protection of water
}

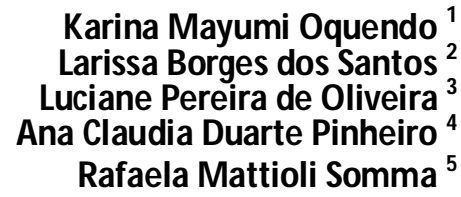

\section{Resumo}

\begin{abstract}
A sociedade tem demonstrado uma crescente preocupação com o meio ambiente, pois compreendeu que os recursos que dele usufrui são de vital importância para a atual e para as futuras gerações. 0 homem passou, então, a entender que era necessário utilizar tais recursos de modo consciente, garantindo o desenvolvimento sustentável, um equilíbrio entre 0 desenvolvimento, com a satisfação das necessidades do homem, e a conservação do meio ambiente. Um dos recursos naturais que o homem mais utiliza é a água. Este recurso hídrico tem valor econômico por ser considerado escasso e é com a necessidade de garantir tal recurso à todos que o direito impõe restrições administrativas e financeiras à sua utilização. A Constituição de 1988 traz em seu bojo os princípios de valorização da água como um bem essencial para a sobrevivência do homem, tornando constitucional seu uso correto. Essas normas possibilitaram o estabelecimento da Política Nacional dos Recursos Hídricos, que ordena tanto o gerenciamento quanto 0 controle administrativo dos recursos. A questão da conservação dos recursos naturais provém de uma conscientização do homem, que, só através da educação ambiental, atua em consonância com princípios de proteção ao meio ambiente, os quais estão regulamentados no ordenamento jurídico.
\end{abstract}

Palavras Chave: Água; Consciência; M eio Ambiente; Recursos; Sustentabilidade.

\begin{abstract}
The company has shown increasing concern for the environment because it realized that it enjoys the resources that are vital for current and future generations. The man then began to understand the need to utilize these resources in a conscious

${ }^{1}$ Discente do 10 ano do curso de Direito da Universidade Estadual de Londrina, Turma 2000, ano de 2007. E-mail: karinaoquendo@ hotmail.com.

${ }^{2}$ Discente do 10 ano do curso de Direito da Universidade Estadual de Londrina, Turma 2000, ano de 2007. E-mail: larissasan@ hotmail.com.

${ }^{3}$ Discente do 10 ano do curso de Direito da Universidade Estadual de Londrina, Turma 2000, ano de 2007. E-mail: lumazzetti@ hotmail.com.

${ }^{4}$ Professora orientadora, mestre em Direito Negocial pela Universidade Estadual de Londrina, professora de Direito Ambiental e Urbanístico da Uel e da Unifil.

${ }^{5}$ Co-orientadora, mestranda em Direito Negocial pela Universidade Estadual de Londrina e especialista em Direito Tributário Internacional pela Universidade de Barcelona. E-mail: rafaela_somma@yahoo.com.br
\end{abstract}


manner, ensuring sustainable development, a balance between development, with the satisfaction of human needs and environmental conservation. One of the natural resources that humans use most is water. This water resource has economic value because it is considered scarce and the need to ensure that all use of the right to impose administrative and financial restrictions on their use. The Constitution of 1988 brings with it the principles of valuing water as a key to the survival of man, making his constitutional right use. These standards have enabled the establishment of the National Policy of Water Resources, which commands both the management and administrative control of resources. The issue of conservation of natural resources comes from an awareness of man, that only through environmental education, acts in accordance with principles of enviro nmental protection, which are regulated by the legal system.

Keywords: Water, Consciousness, Environment, Resources, Sustainability.

\section{Introdução}

A degradação ambiental a que chegamos despertou a humanidade, revelando a realidade de um planeta limitado e deteriorado pelas várias sociedades que o povoam e 0 exploraram.

O homem enfrenta hoje uma séria crise ambiental, uma vez que a qualidade de vida entra em conflito com a gestão e as tecnologias utilizadas para explorar o meio ambiente.

0 uso desmedido dos recursos naturais, já começou a surtir efeitos.

0 efeito estufa, oriundo da poluição de responsabilidade difusa, as mudanças climáticas e as catástrofes ecológicas que afetam o mundo todo demonstram a crise ambiental, que passou de indagação em 1960, a fato comprovado em 1970.

Desse modo, faz-se essencial a criação de uma ética ambiental positivada pelo direito, com uma educação voltada para a consciência ecológica. É preciso que o homem compreenda a necessidade de preservar ou conservar os recursos naturais essenciais à perpetuação de todas as espécies de vida existentes no planeta.

Surge, com isso, o chamado Direito Ambiental, como característica de solidariedade, que visa à proteção jurídica de um bem autônomo pertencente a todo 0 planeta, logo que as ações praticadas em um local isolado surtirão efeitos em todo o globo.

Uma vez que os recursos naturais são escassos e o homem a cada dia degrada mais o meio em que vive, cabe ao Estado criar um controle na qualidade de vida e proteger, através de uma educação ambiental e políticas públicas, o meio ambiente.

Porém, os interesses econômicos prevalecem sobre os assuntos que não deveriam 
ser deixados de lado, como a preservação da água, já que sem ela o homem está sujeito ao desaparecimento.

\section{Educação ambiental}

Segundo José de Ávila Aguiar Coimbra (2002, p.32), Meio Ambiente compreende 0 conjunto dos elementos físicos, químicos e biológicos e de suas inúmeras relações, ordenada para a perpetuação da vida e organizada em ecossistemas naturais e sociais, constituindo uma realidade complexa e marcada pela ação da espécie humana. E para que esse possa ser conservado, a Educação Ambiental é de extrema importância.

0 primeiro passo foi dado a partir da regulamentação do art. 225, § 1으, VI, da CF pela Lei n. 9.795, de 27 de abril de 1999, que institui a Política Nacional de Educação Ambiental e incumbe o Poder Público de realizar programas de educação e conscientização pública, nos mais variados níveis de ensino, para a preservação do meio ambiente.

A Educação ambiental é um processo por meio do qual o indivíduo e a coletividade constroem valores sociais, conhecimentos, habilidades, atitudes e competências voltadas à conservação do meio ambiente, bem como o de uso comum dos recursos pelos povos, essencial à sadia qualidade de vida e sua sustentabilidade (art. $1^{0}$ da Lei n. 9.795/99 - g.n.).

Valores como o de conservar e o de preservar devem fazer parte da educação ambiental. De maneira que o primeiro busca explorar economicamente os recursos naturais de forma racional, sem causar desperdício. E o segundo, visa à proibição da exploração econômica dos recursos naturais.

Assim, a política da sustentabilidade é primordial, uma vez que caracteriza a utilização racional dos recursos naturais sem degradar o meio ambiente.

0 biocentrismo deve prevalecer sobre 0 antropocentrismo, uma vez que o primeiro compreende a flora, a fauna e a biodiversidade como sujeitos de direito, necessitando de proteção judicial. Já no antropocentrismo o homem é o centro das preocupações ambientais. Porém, sem a proteção do biocentrismo, o homem pode deixar de existir. Logo, ambos devem atuar de maneira complementar, pois a natureza protegida garante a vida atual e das gerações futuras.

É necessário, então, que o desenvolvimento sustentável seja incutido no cerne da consciência populacional. Este é um processo linear e progressivo, que leva a população ao 
crescimento, através do aproveitamento dos seus distintos valores e potencialidades. Deve ocorrer de forma global e harmonizada em todos os campos sociais, de modo a produzir e distribuir os bens e serviços necessários à satisfação das necessidades individuais e coletivas por meio de um aperfeiçoamento técnico e cultural, que visa a melhor forma de preservação.

\section{Desenvolvimento e meio ambiente}

O modelo de desenvolvimento que era adotado pelo Brasil de "evolução a qualquer custo", ainda que à custa da degradação ambiental, foi responsável por uma série infinita de alterações na Natureza, algumas irreversíveis, tendo em vista o desaparecimento de espécies animais e vegetais, nunca conhecidas, únicas em todo o mundo. Também acarretou profundos desequilíbrios sociais. Um exemplo claro, são as grandes diferenças que existem entre as populações mais e menos favorecidas.

É evidente que países ricos queiram impor a idéia de não-desenvolvimento aos países pobres, com 0 argumento de que não contribuam para o aumento da poluição em nível mundial. 0 Brasil, por exemplo, repeliu essa opinião, em documento oficial, alegando que os maiores índices de poluição são de responsabilidade das nações industrializadas e com o agravante de que só recentemente adotaram medidas de proteção ao meio ambiente.

Nesse sentido, com a necessidade de conciliar desenvolvimento econômico e preservação, surge a Lei 6.938, de 31.8.1981 (arts.1ำ e 4ํ) pondo como o principal objetivo da Política Nacional do Meio Ambiente a compatibilização do desenvolvimento econômicosocial com a preservação da qualidade do meio ambiente e do equilíbrio ecológico. Este objetivo leva à promoção do chamado desenvolvimento sustentável.

Tal forma de desenvolvimento implica um crescimento econômico, mas com vistas a uma redistribuição dos resultados do processo produtivo e a erradicação da pobreza, de forma a reduzir as disparidades nos padrões de vida e melhor atendimento da maioria da população.

Desenvolvimento sustentável

Na década de 70, uma equipe de cientistas do Instituto de Tecnologia de 
Massachussets encaminhou ao Clube de Roma, em 1974, um relatório denominado "The Limits of Growth", com grande repercussão internacional.

0 "Relatório Meadows" exerceu forte influência na elaboração dos estudos preliminares para a Conferência de Estocolmo, que estabeleceu, em seus princípios, o planejamento de seu desenvolvimento, para compatibilizar a necessidade de proteger e melhorar o ambiente. Até então, no Brasil, o desejo de desenvolvimento tinha prioridade sobre qualquer outra preocupação, inclusive o meio ambiente.

A fim de conciliar o progresso das relações econômicas à urgência de proteger os recursos naturais, os estudiosos foram levados ao conceito de desenvolvimento sustentável, em que se permite e se encoraja o desenvolvimento, desde que adequado a normas de proteção ambiental em todas as ações e atividades. Isto garante a permanência do equilíbrio ecológico e da qualidade da vida humana, até mesmo para as futuras gerações.

Esse princípio de desenvolvimento sustentável possui interfaces com a outorga do direito de uso da água, o licenciamento ambiental, os usos múltiplos, a noção de bacia hidrográfica como unidade de planejamento e gerenciamento.

\section{Água no ordenamento jurídico}

Os múltiplos usos das águas sem a ocorrência de conflitos têm sido considerado 0 ideal, pois é dessa forma que se obterão resultados não só técnicos, mas também sociais. Veiga da Cunha diz que as prioridades devem ser:

[...] os aproveitamentos de recursos hídricos para fins múltiplos e objetivos múltiplos, tendo em vista designadamente a otimização dos investimentos; em particular, a construção de novos aproveitamentos hidrelétricos deve ser precedida de um estudo pormenorizado das necessidades agrícolas, industriais e municipais da área interessada. (apud GRANZIERA, 2003, p.62)

A água possui valor por haver interesse nela e ainda tem caráter econômico quando se torna escassa. A declaração de Dublin trata dessa matéria. Assim, em seu Princípio 4:

[...] a água tem valor econômico em todos os seus usos e deve ser reconhecida como um bem econômico. De acordo com esse princípio, é vital reconhecer como prioritário o direito básico de todo ser humano a ter acesso à água potável e ao saneamento, a um preço acessível. No passado, o não-reconhecimento do valor econômico da água conduziu ao seus desperdício e a danos ambientais decorrentes do seu uso. A gestão da água, como bem econômico, é uma importante forma de 
atingir a eficiência e eqüidade no seu uso e de promover a sua conservação e proteção. (apud GRANZIERA, 2003, p.56)

Juridicamente falando, a água também consiste num bem ou coisa.

A água é um recurso de natureza escassa. 0 homem necessita dela para desenvolver-se e sobreviver, assim, cada vez mais pessoas precisam dos recursos hídricos, o que pode resultar em intensos conflitos, já que a água não está disponível a todos, tanto quantitativamente, como qualitativamente.

O Direito, desse modo, evolui para inserir valor à água e para impor, em sua utilização, restrições. Seja de cunho administrativo, ou de natureza financeira. As fontes do direito de águas são: a lei, a doutrina e a jurisprudência, assim como os tratados internacionais.

Com isso, novas preocupações surgem constantemente e com elas, o conceito de direito de águas evolui. Cid Tomanik Pompeu (apud GRANZIERA, 2003, p.24) define o direito de águas como um "conjunto de princípios e normas jurídicas que disciplinam

o domínio, uso, aproveitamento e preservação das águas, assim como a defesa de suas danosas conseqüências". Já Maria Granziera (2003, p.24), define 0 direito de águas como:

[...] o conjunto de princípios e normas jurídicas que disciplinam o domínio, as competências e o gerenciamento das águas, visando ao planejamento dos usos e à preservação, assim como a defesa de seus efeitos danosos, provocados ou não pela ação humana.

Princípios aplicáveis à água

Assim, são formulados princípios, que constituem as bases para as diretrizes a adotar na elaboração das normas jurídicas. São princípios e normas que, segundo Mario Tavarela Lobo (apud GRANZIERA, 2003, p.43), informam sobre a atuação do Estado no âmbito da gestão da água, tendo como objetivo a exploração e planificação, a conservação e maximização dos recursos hídricos.

Há grande importância das normas ambientais em matéria de conservação da água. Toda a principiologia sobre as águas tem sua origem nos tratados internacionais. As regras fixadas na Lei no. 9.433/97 fundamentam-se em princípios formulados no âmbito do direito 
internacional.

Das declarações que procederam das muitas conferências, como a Conferência de Estocolmo sobre M eio Ambiente, de 1972 e a Conferência Rio/92, dois tipos de princípios se destacam: os que devem ser observados pelos Estados, diante dos demais e os a serem adotados internamente, na busca de soluções para minimizar os efeitos da poluição e da degradação ambiental, que afetam a comunidade internacional, pois não há fronteiras para o meio ambiente. De acordo com Bobbio, pensador italiano:

[...] a formulação das normas sobre meio ambiente e recursos hídricos, editadas nas últimas décadas, em vários países, inclusive no Brasil, resultaram de uma resposta às necessidades experimentadas pela sociedade, que decidiu ser 0 momento de mudanças no enfoque das relações 'homem-natureza. (apud GRANZIERA, 2003, p. 45)

Até então, a preocupação era a de preservar a natureza para o desfrute do homem, ficando o meio ambiente dissociado do ser humano, que o domina. Mas hoje não é esta idéia que prevalece. Pelo contrário, "o ambiente é algo inseparável do homem. 0 simples modo de ser transmite algo de seu próprio ao ambiente, influenciando-o ora negativamente ora positivamente". (2002, p.10-11).

Princípio da prevenção

Michel Prieur (apud GRANZERA, 2003, p.49) afirma que a prevenção consiste em: “impedir a superveniência de danos ao meio ambiente por meio de medidas apropriadas, ditas preventivas, antes da elaboração de um plano ou da realização de uma obra ou atividade".

Havendo uma análise prévia dos impactos que determinado empreendimento pode causar ao meio ambiente é possível, por meio da adoção de medidas compensatórias, e mesmo da alteração do projeto em análise, se for o caso, assegurar sua realização, garantindo-se os benefícios econômicos do mesmo decorrentes, sem causar dano ao meio ambiente. Ou seja, assegurar o desenvolvimento, prevenindo danos futuros.

A melhor reflexão desse princípio, no campo normativo brasileiro, é o Estudo Prévio de Impacto Ambiental, fixado na Lei $n \div$. 6.938/81, como um dos instrumentos da Política Nacional do Meio Ambiente e posteriormente alçado à categoria de norma constitucional, 
no art. 225, inciso IV. É um preceito que dispõe sobre "exigir, na forma da lei, para instalação de obra ou atividade potencialmente causadora de significativa degradação do meio ambiente, Estudo Prévio de Impacto Ambiental, a que se dará publicidade". Assim, a prevenção consiste em agir contra o risco de potencial produção de efeitos nocivos.

Princípio da precaução

O termo "precaução" significa prudência, cuidado, cautela antecipada. São seus elementos que compõem exatamente o que se chama de proteção ao meio ambiente, para as atuais e futuras gerações.

Com o intuito de evitar novas e desagradáveis surpresas em matéria de degradação ambiental, existe o princípio da precaução para determinar que, na dúvida, é melhor tomar providências drásticas, a fim de evitar danos futuros, por ignorância das conseqüências que certos empreendimentos e substâncias podem causar. Havendo, assim, maior probabilidade de ocorrência de danos, e de acordo com a natureza do dano em potencial, a atividade não deve ser licenciada.

Princípio da cooperação

Este princípio prega a soma de esforços. Cabe aos Estados, que compartilham os recursos naturais, atuarem de forma coordenada, mesmo no que se refere às ações internas, para evitar a ocorrência de danos, assim como para racionalizar as medidas de proteção que se fizerem necessárias.

Desse modo, estabelecem-se acordos, convênios e contratos para que a disciplina ambiental seja eficaz e autêntica. Portanto, de acordo com Veiga da Cunha:

[...] a maioria dos acordos internacionais celebrados referem-se mais a direitos e obrigações dos países relativamente à água do que às formas de cooperação na gestão dos recursos hídricos em nível das bacias hidrográficas internacionais. Essa cooperação não pode, aliás, ser efetiva, antes de serem convenientemente definidos aqueles direitos e obrigações, o que nem sempre é fácil de conseguir a contento das partes interessadas. (apud GRANZIERA, 2003, p.52)

Essa cooperação deve ocorrer por meio de tratados específicos, em que os Estados limítrofes estabelecem formas conjuntas de atuar. Está presente em vários campos e é previsto nas conferências, até mesmo em alguns artigos da Constituição: um exemplo é o 
art. 23, que dispõe sobre a competência comum da União, Estados, Distrito Federal e Municípios, para proteger o meio ambiente e combater a poluição, tendo em vista 0 equilíbrio do desenvolvimento e do bem-estar no âmbito nacional.

0 art. 225 também estabelece implicitamente a cooperação, à medida que impõe ao Poder Público e à coletividade o dever de defender e proteger o meio ambiente para as presentes e futuras gerações.

\section{A política nacional de recursos hídricos}

É fundamental entender a diferença existente entra águas e recursos hídricos. Para Cid Tomanik Pompeu (apud GRANZERA, 2003, p.27), o termo "águas" aplica-se quando não existe o comprometimento com seu uso ou utilização e, a expressão "recursos hídricos", refere-se ao caso de haver aproveitamento econômico.

A água representa um elemento natural do planeta, assim como o petróleo. Logo, não é um recurso, nem possui qualquer valor econômico. É somente a partir do momento em que se torna necessário a uma destinação específica, de interesse para as atividades exercidas pelo homem, que esse elemento pode ser considerado um recurso.

No entanto, a Lei no 9.433/97 não distingue o termo “água" da expressão "recursos hídricos". Em ser art. 1ำ dispõe que a "água" é um bem de domínio público. Fala em uso prioritário e gestão dos "recursos hídricos", mas menciona que a "água" é um recurso natural limitado, dotado de valor econômico.

A Constituição Federal de 1988 traz uma mudança significativa de concepção sobre o meio ambiente e de sua proteção legal. As novas normas possibilitaram o estabelecimento da Política Nacional de Recursos Hídricos expressa na Lei $n \cong$ 9.433/97 art. 1ํ․

\footnotetext{
I - a água é um bem de domínio público;

II - a água é um recurso natural limitado, dotado de valor econômico;

III - em situações de escassez, o uso prioritário dos recursos hídricos é o consumo humano e a dessedentação dos animais;

IV - a gestão dos recursos hídricos deve proporcionar o uso múltiplo das águas;

V - a bacia hidrográfica é uma unidade territorial para implementação da Política Nacional de Recursos Hídricos e atuação do sistema Nacional de Gerenciamento dos Recursos Hídricos;

$\mathrm{VI}$ - a gestão dos recursos hídricos deve ser descentralizada e contar com a participação do Poder Público, dos usuários e das comunidades.
} 
Os princípios apresentados evidenciam que a nova concepção legal busca encerrar com a apropriação privada dos recursos hídricos. Os grandes usuários destes recursos, a indústria e a agricultura, normalmente, utilizam-se da água e depois a devolvem para o seu local de origem sem a devida preocupação com a manutenção das condições sanitárias e ambientais.

A recuperação da água utilizada fica a cargo de toda a sociedade, que com seus impostos, subsidia, de forma inaceitável, diversas atividades privadas. Por isso, além do planejamento como forma de orientar o uso das águas, organizando situações de conflito, cabe a um controle administrativo a função de evitar danos futuros ao meio ambiente na questão relativa à água da parte privada para com a sociedade como um todo.

\section{Gerenciamento de recursos hídricos}

Faz-se necessário a existência de Políticas Nacionais de Recursos Hídricos, conforme cita os inciso I I ell do art. $2^{\circ}$ da Lei 9.433/1997.

O desenvolvimento sustentável torna-se indispensável, uma vez que a água é um bem de domínio público, um recurso natural escasso que possui valor econômico. Por isso, deve ser gerenciado de maneira correta, com prioridades a serem sanadas, como por

exemplo, em casos de escassez a prioridade é o consumo humano e dessedentação dos animais.

Proteger a Bacia Hidrográfica é essencial, já que ela faz parte da unidade territorial, que deve sempre ser gerenciada pelas Políticas de Recursos Hídricos, que possuem poder descentralizados e necessitam da participação do Poder Público, dos usuários, da população em geral, para que se possa ter uma atuação eficaz.

Como cita Paulo A. L. Machado, (2002, p. 39). “A Lei 9.433/1977 demarca concretamente a sustentabilidade dos recursos hídricos em três aspectos: disponibilidade de água, utilização racional e utilização integrada". Logo as Políticas Nacionais de Recursos Hídricos têm como principal objetivo, assegurar às futuras gerações e disponibilidade de água, dentro dos padrões necessários de qualidade adequada para cada tipo de uso. Garantia que será alcançada se houver utilização racional e adequada dos recursos existentes, para que se possa, também, prevenir e defender, contra qualquer crise que possa vir a prejudicar os recursos hídricos. 
Existem instrumentos para a concretização dos objetivos acima citados, que são de acordo com 0 art. 50: classificar os corpos de água em classes, levando em consideração a essencialidade da água em cada caso; regulamentar o uso, a preservação e a recuperação dos Recursos Hídricos; dar concessão racional para uso dos recursos hídricos; tributar pelo uso destes recursos; compensar os municípios e, utilizar o sistema de informação dos Recursos Hídricos.

Segundo Ana Cláudia B. Graf (FREITAS, 2006, p.67), o Conselho Nacional de Recursos Hídricos é composto pelos conselhos de recursos hídricos dos Estados e do Distrito Federal, pelos comitês de bacia hidrográfica, pelos órgãos de poderes públicos federais, estaduais e municipais. Seu papel é o de cuidar dos assuntos relacionados à água e pelas agências nacionais de águas, que decidirão sobre o planejamento e gerenciamento de sua utilização, tanto relacionados com 0 abastecimento, como também com a produção de energia, uso industrial, transporte, irrigação etc.

Além disso, é necessário que se façam os balanceamentos da disponibilidade dos recursos; cadastros dos usuários das águas; analisar e informar sobre projetos, sempre acompanhando a administração desses recursos; elaborar propostas orçamentárias; promover os estudos essenciais; elaborar o Plano de Recursos Hídricos para apresentar ao comitê que decidirá sobre a sua implantação etc.

Algumas diretrizes deverão ser seguidas para a implantação da Política Nacional dos Recursos Hídricos, como está disposto no art. 3o da Lei 9.433/1997, ao

mencionar sobre a necessidade de várias etapas a serem seguidas antes da outorga do direito do uso das águas, da elaboração do Plano de Recursos Hídricos e da realização de cobranças pela utilização da água.

A gestão deverá levar em conta aspectos como as condições demográficas, econômicas, físicas, bióticas, sociais e culturais da região onde deverá ser implantada. E, ainda, possuir caráter sistemático e abrange temas como qualidade e quantidade.

Portanto, os recursos hídricos não podem ser geridos excluindo o resto do meio ambiente, devem buscar proteger, também, a fauna e a flora, contra o uso de agrotóxicos, a instalação de indústrias, entre outros inúmeros fatores.

No entanto, gerenciar a utilização dos recursos hídricos com seriedade e de forma racional é o principal meio para se preservar as águas e fazer com que as gerações futuras 
possam desfrutar desse bem ambiental, já que este é um bem de todos, como cita Fiorillo (2004, p. 51):

[...] um bem que tem como característica constitucional mais relevante ser essencial à sadia qualidade de vida, sendo ontologicamente de uso comum do povo, podendo ser desfrutado por toda e qualquer pessoa dentro dos limites constitucionais.

Bacia hidrográfica como instrumento de planejamento e gestão

Quando se usa o termo bacia hidrográfica, não se limita a um único rio, visa também a seus afluentes. Já a idéia de "bacia integrada", introduzida pela International Law Association, em Dubrovnik, em 1956, em seu princípio 8 estabelece:

Na medida do possível, os Estados ribeirinhos devem cooperar, visando assegurar a exploração completa dos recursos hidráulicos e, para essa finalidade, de uma parte, considerar a bacia fluvial como um todo a integrar e, de outra, não negligenciar qualquer utilização possível da água, de maneira que todos os interesses tirem 0 máximo de proveito. (apud GRANZIERA, 2003, p.60)

Para tanto, a citada cooperação, deve sempre existir entre os usuários de uma bacia hidrográfica, para esse melhor aproveitamento dos recursos hídricos. Isso deve ocorrer no intuito de proporcionar um melhor desenvolvimento econômico e social à região.

\section{0 controle administrativo da utilização das águas}

O uso da água, como foi citado acima, deve ser administrado de modo que seu exercício assegure a existência desta para as atuais e futuras gerações. Tem por objetivo evitar que a má utilização das águas provoque danos ao meio ambiente, fundamentando-se essencialmente nos instrumentos juridicamente estabelecidos por parte do poder Público, ou seja, tem como base as leis e decisões provenientes do sistema de gerenciamento dos recursos hídricos. Estabelece, portanto, limites e condições para o controle do uso das águas.

No que se refere à administração de sua utilização, dizemos que esta pode ser designada como poder de polícia. O Código Tributário Nacional estabelece a definição de poder de polícia: 
Art. 78. Poder de polícia é a atividade da administração pública que, limitando ou disciplinando direito, interesse ou liberdade, regula a prática de ato ou abstenção de fato, em razão de interesse público concerne à segurança, à higiene, à ordem, aos costumes, à disciplina da produção e do mercado, ao exercício de atividades econômicas dependentes de concessão ou autorização do Poder Público, à tranqüilidade pública ou ao respeito à propriedade a aos direitos individuais ou coletivos.

A partir das leis já fixadas no ordenamento jurídico, cabe ao poder de polícia das águas estabelecerem regulamentos que proporcionem não só sua atividade administrativa, como também a aplicação de penalidades no caso de desrespeito às regras instituídas. Tal poder é exercido pela União, Estados e Distrito Federal pelo fato destes serem os detentores do bem público ou como papel de ente regulador, com a finalidade de evitar danos futuros. Como Cid Tomanik Pompeu (apud GRANZIERA, 2003, p.171) conclui:

[...] ao exercerem o poder de polícia sobre as águas públicas, a União e os Estados têm dupla posição: a primeira, na qualidade de titulares do domínio do respectivo bem público água; a segunda, na de poderes públicos encarregados, concorrentemente, da defesa e proteção da saúde da coletividade.

Cabe também ao Estado autorizar o uso das águas aos interessados, sejam eles pertencentes à esfera pública ou particular, concedendo ou não a outorga do direito de uso das águas. Outorgado o uso, determina os limites dessa utilização e fiscaliza o cumprimento da regra vigente. 0 poder de outorga do Estado permite um maior controle das atividades que utilizam os corpos hídricos, como o controle sobre a captação e a utilização das águas.

O licenciamento ambiental constitui-se também em instrumento de controle, no que se referem aos despejos nos corpos hídricos, assim como à sua proteção. Fundamentase nos princípios da preservação da supremacia do interesse público sobre o particular, pois uma atividade só deverá ser licenciada se estiver de acordo com as normas, critérios, padrões e princípios da legislação ambiental, ou seja, estiver de acordo com o interesse público. Sua função é de garantir que a atividade econômica se realize sem causar danos ao meio ambiente, exigindo, assim, o cumprimento por parte do empreendedor de vários requisitos ambientais. 


\section{A tributação ambiental}

A atividade tributária do Estado, até recentemente vista pela doutrina nacional internacional apenas do ponto estritamente jurídico, agora encontra uma função finalística clara e nobre, a proteção do meio ambiente.

Já para a cobrança pela utilização do uso dos recursos hídricos, isto já acontece, pois tal cobrança não constitui um fim em si mesmo, mas ao contrário, um instrumento utilizado para 0 alcance de finalidades precisas. A cobrança, então, não tem a natureza de tributo.

Para José Afonso da Silva (apud FERNANDEZ, 2006, p.466), o conceito de meio ambiente compreende não apenas o meio ambiente natural, mas também o cultural e o artificial, aí incluídos as edificações, o patrimônio histórico, artístico e paisagístico.

Assim podemos concluir que há tempos já existe tributação ambiental no Brasil, pois o ITR (Imposto sobre a Propriedade Territorial Rural) de competência da União Federal e o IPTU (Imposto sobre a Propriedade Predial e Territorial Urbana) de competência dos M unicípios, já cumprem esse papel de regulação da atividade econômica com vistas à defesa do meio ambiente.

Conforme o Código Tributário Nacional define no Art. 3o: "Tributo é toda prestação pecuniária compulsória, em moeda ou cujo valor nela se possa exprimir, que não constitua sanção de ato ilícito, instituída em lei e cobrada mediante atividade administrativa plenamente vinculada".

A cláusula, "que não constitua sanção de ato ilícito", significa uma delimitação ao regime jurídico tributário, que exclui as multas e as indenizações ao Poder Público. 0 ato ilícito é a infração de um dever legal, a violação do direito de forma voluntária. Então, os danos causados ao meio ambiente não podem ser matéria de tributação ambiental, pois assim, constituiriam em multas e indenizações.

Mas, a Constituição Federal de 1988, prevê que a regulação da atividade econômica, por meio de fomento, fiscalização e planejamento, seja feita pelo Estado, assim o tributo pode ser utilizado na condição de instrumento econômico regulátorio de atividades prejudiciais ao meio ambiente.

Aprofundando o conceito de tributação ambiental Roberto Ferraz conceitua os green taxes como tributos ecologicamente orientados, definem que no custo de cada bem 
ou mercadoria estaria acrescentado ao seu valor o custo que seu consumo representa em termos ambientais, estes custos ambientais seriam, portanto, os green taxes. 0 valor final, influencia, então, na decisão econômica, de modo a tornar mais interessante a opção ecologicamente mais adequada.

Mas o simples aumento dos impostos incidentes em tais produtos não é, isoladamente, medida segura de proteção ambiental, pois não pode ser mais uma fonte de arrecadação do Estado. Tem de haver um órgão fiscalizador que repasse o valor do tributo ambiental para a proteção do meio ambiente.

\section{Integração tributária}

A partir do momento em que interesses nacionais e externos se coincidem, há uma integração dos Estados-Membros, e conseqüente harmonização de seus ordenamentos jurídicos. Da integração desses países, formam-se os blocos econômicos regionais, como o MERCOSUL, que tem como objetivo um bem comum.

A integração dessas nações possibilita uma adequação de conceitos e de leis de forma a facilitar uma maior reciprocidade de contribuições entre os membros do bloco; temse assim, uma harmonização legislativa.

Outra questão discutível nos blocos econômicos é a do meio ambiente. Esta, não está restrita a um país, pois os danos ambientais e suas conseqüências não se limitam às fronteiras. Também a questão da natureza tributária é um assunto que abrange interesses de várias nações pertencentes a um bloco.

Para M aria Fátima Ribeiro (apud PINHEIRO, 2005, p.125.), as questões de natureza tributária estão relacionadas com a legislação ambiental:

[...] vale a pena ressaltar que a harmonização tributária não significa equalização total de alíquotas e bases tributárias em vários países e em todos os tributos. 0 que se pretende é obter um mercado globalizado que seja consistente com o menor grau possível de distorções. Nesse sentido, há a necessidade de aproximar a legislação tributária pertinente entre todos os paises membros do M ERCOSUL.

Os blocos econômicos regionais são de grande importância para harmonia dos interesses diversos, pois constitui uma integração de nações, que apresentam objetivos comuns, dentre eles o meio ambiente. 
Cobrança pela utilização dos recursos hídricos

A cobrança pelo uso da água não significa que 0 pagador tenha 0 direito de apropriar-se da água, pois, como dito anteriormente, a água é um bem público e apenas por meio de outorga, confere o direito ao uso para particulares. Nos casos de uso da água para as primeiras necessidades ou para pequenos núcleos populacionais onde a captação, lançamento e também a acumulação de volumes de água são considerados insignificantes, não há a necessidade de outorga.

0 usuário dos recursos hídricos que, através da utilização dos mesmos, provocar alteração na quantidade e na qualidade da água, causando, assim, danos, é considerado poluidor, e deverá recuperar e indenizar tais danos causados. Há também a utilização dos recursos ambientais para fins econômicos, como uma atividade que simplesmente utiliza o rio, servindo de passagem, como se fosse uma estrada. Remete, então, a dois princípios: "poluidor-pagador" e "usuário-pagador".

A Lei das Águas em seu art. 12 traz os critérios dos valores a serem cobrados, os quais devem ser observados, entre outros, nas derivações, captações e extrações de água, 0 volume retirado e seu regime de variação. $E$, ainda, os lançamentos de esgotos e demais resíduos líquidos ou gasosos, o volume lançado e seu regime de variação e as características físico-químicas, biológicas e de toxidade do afluente.

O objetivo da cobrança é arrecadar recursos financeiros necessários ao desenvolvimento de atividades que visem o planejamento do uso das águas, ou seja, com esses recursos financeiros é possível a realização das propostas do plano de gerenciamento de recursos hídricos.

No plano federal, cabe à Agência de Águas efetuar tal cobrança, mediante autorização do outorgante, ou seja, autorização do detentor do domínio do recurso, que é a União ou os Estados. Também cabe à União ou aos Estados autorizar, e assim, atribuir capacidade administrativa à entidade que estiver exercendo a função de cobrança. Tal competência deve ser objeto de regulamentação.

Conforme dispõe 0 art. 4º, inciso VIII e IX da Lei no 9.984/2000:

[...] à Agência Nacional de Águas - ANA cabe implementar a cobrança pelo uso dos recursos hídricos, em articulação com os Comitês de Bacia Hidrográfica, assim, 
como arrecadar, distribuir e aplicar receitas auferidas por intermédio da cobrança quanto ao uso de recursos hídricos de domínio da União.

Poluidor-pagador e usuário-pagador

Com o aumento da degradação e escassez da água no mundo, se fez necessário coibir o desperdício e controlar seu uso. Ao longo do tempo, a bacia hidrográfica transformou-se em unidade básica de planejamento e gestão.

No princípio poluidor-pagador, os usuários têm o direito a um ambiente limpo, enquanto os poluidores não possuem o direito de efetuar descargas de resíduos. Dessa forma, o poluidor deve pagar, na proporção das descargas que efetua. Mas isso não significa que quem pode pagar mais pode poluir mais. Os instrumentos econômicos, por si só, não eliminam a necessidade de um programa de monitoramento e fiscalização. Devem, assim, existir limites quantitativos e qualitativos para as descargas de rejeitos.

O princípio do poluidor-pagador, segundo Michel Prieur (apud GRANZERA, 2003, p.57), inspirou-se na teoria econômica, na qual os custos sociais externos que acompanham a produção industrial devem ser contabilizados junto com os outros custos da produção.

Já o princípio "usuário-pagador" é o de que os recursos ambientais existem para 0 benefício de todos. Assim, todos os usuários sujeitam-se à aplicação dos instrumentos econômicos estabelecidos para regular seu uso. Seria o pagamento pelo uso privativo de bem público, em detrimento dos demais interesses.

Quanto será cobrado é definido depois de haver uma compatibilização entre 0 princípio do ônus social e o do poluidor-usuário-pagador. Caso seja impossível ou extremamente oneroso ao poluidor assumir todos os custos da poluição que o mesmo provoca, há que definir um limite para esse pagamento, sendo que o restante será assumido pelo Poder Público e financiado pela comunidade.

Contudo, nos dias de hoje, o Poder Público vem assumindo todos os custos da poluição causada, sendo que "devem procurar promover a internalização dos custos ambientais e o uso de instrumentos econômicos, levando na devida conta o interesse público, sem distorcer o comércio e os investimentos internacionais", de acordo com Geraldo Eulálio Nascimento Silva (apud GRANZERA, 2003, p.59). Cabe à indústria investir em estações de tratamento de efluentes. 


\section{Conclusão}

Resguardar os Recursos Hídricos, assim como todo o meio ambiente, é garantia de seguridade da vida no planeta.

A utilização dos bens naturais é necessária para a sobrevivência dos seres vivos, como também sua utilização de forma irracional poderá acarretar problemas tanto no presente como nos dias que estão por vir, ou seja, as conseqüências tanto podem ser notadas de maneira imediata quanto futura.

É direito do ser humano utilizar a água para as suas necessidades fundamentais. Negar-Ihe este bem é condená-lo a morte, ferindo, assim, seu direito prioritário de viver.

Por ser um recurso natural limitado, a água passou a ser vista como um bem econômico, o que não significa que quem pode pagar por ela terá a possibilidade de poluir, de esgotar, ou utilizá-la para fins e interesses particulares.

A água, porém, não deve ser vista apenas como um bem econômico, pois ela é essencial à vida humana e um valor como a vida não pode ser quantificado.

A valorização da água se deu pela necessidade de se cobrar pelo preço de sua conservação, da sua recuperação, da melhor distribuição e para que seja respeitada por todos, uma vez que a conscientização parece chegar mais fácil quando o homem percebe que há um prejuízo que atinge diretamente seu bolso.

Nesse sentido, é através do controle do Poder Público sobre a gestão das águas, da cobrança de tributos, e da administração dos bens naturais, que resultados mais eficientes no campo da preservação serão alcançados.

Cabe às políticas de gerenciamento dos recursos hídricos fazer com que a água seja aproveitada, essencialmente, de maneira racional. 0 gestor público, desta forma, fica com a responsabilidade de avaliar e outorgar sobre a sua utilização correta.

Todavia, faz-se imprescindível a criação de programas eficazes e sérios de preservação e conservação do meio ambiente, assim como a criação de uma educação ambiental que conscientize toda a população desta eminente necessidade.

Tributar, gerenciar, administrar, educar de forma séria e concisa a utilização dos recursos hídricos são apenas formas de tentar prevenir que estes bens escassos sejam extintos devido à ganância e ignorância humana. 
Com isso, é necessário que haja um controle jurídico, não só das águas, como também, de todos os bens ambientais, pois sem estes, uma qualidade de vida saudável e digna para todos, continuará sendo o que sempre foi: uma utopia.

\section{Referências}

ANTUNES, Paulo de Bessa. Direito Ambiental. 8ąed. Rio de Janeiro: Lúmen Júris, 2006.

COIMBRA, José de Ávila Aguiar. 0 outro lado do meio ambiente: uma incursão humanista na questão ambiental. Campinas: Millenium, 2002.

FERNANDEZ, German Alejandro San Martín. Direito internacional tributário ambiental e a adequação da legislação e da doutrina nacional ao princípio do poluidor pagador. In. CASSELA, Paulo Borba. Direito da Integração. São Paulo: Quartier Latin, 2006.

FERRAZ, Roberto. Tributação e meio ambiente: 0 green tax no Brasil (Contribuição de intervenção da emenda 33/2001). In. M ARINS, James (Coord.). Tributação e M eio Ambiente. Curitiba: Juará, 2002.

FIORILLO, Celso Antônio Pacheco. Curso de Direito Ambiental Brasileiro. 5ạed. São Paulo: Saraiva, 2004.

FREITAS, Vladimir Passos de. Águas: aspectos jurídicos e ambientais. 2ªed. Curitiba: Jaruá, 2006.

GRANZIERA, Maria Luiza Machado. Direito de Águas: disciplina jurídica das águas doces. 2ed. São Paulo: Atlas, 2003.

LEITE, José Rubens M orato; AYALA, Patryck de Araújo. Novas Tendências e possibilidades do direito ambiental no Brasil. In WOLKM ER, Antônio Carlos; LEITE, José Rubens Morato (org.). Os novos direitos no Brasil. São Paulo: Saraiva, 2003.

M ACHADO, Paulo Affonso Leme. Recursos Hídricos: Direito Brasileiro e Internacional. São Paulo: Malheiros, 2002.

PINHEIRO, Ana Claudia Duarte; BASSOLI, M arlene Kempfer. Sustentabilidade econômica e ambiental: um ideal da sociedade internacional. In. Scientia luris - revista do curso de mestrado em Direito Negocial da Uel, Londrina, v.9, 2005.

SIRVINKAS, Luis Paulo. M anual de Direito Ambiental. 3a ed. São Paulo: Saraiva, 2005. 